\title{
Development of an integrative learning program for community dwelling old people with dementia*
}

\author{
Thomas Kwok Shing Wong $1,2,3$ \\ (iD) https://orcid.org/0000-0002-3803-0833 \\ Yang Yunhua ${ }^{2}$ \\ (iD) https://orcid.org/0000-0001-7462-4164 \\ Chen Jinghan ${ }^{4}$ \\ (iD) https://orcid.org/0000-0003-4626-6501 \\ Carmen Ka Man Lee ${ }^{5}$ \\ (iD) https://orcid.org/0000-0002-6625-5749 \\ Zhou Ying \\ (iD) https://orcid.org/0000-0002-7084-8379 \\ Jiang Liping ${ }^{6}$ \\ (iD) https://orcid.org/0000-0003-2782-7051 \\ Tang Qiubi' \\ (D) https://orcid.org/0000-0002-9481-7841 \\ Joanne Wai Yee Chung 1,7 \\ (D) https://orcid.org/0000-0001-9884-9800
}

* This article refers to the call "Nursing Now and Nursing in the Future". Supported by Ginger Innovative Programs for Old People Grants, Grant \# 20160612, China.

${ }^{1}$ Guangzhou Medical University, Guangzhou, Guangdong, China.

${ }^{2}$ Guangzhou University of Chinese Medicine, Guangzhou, Guangdong, China.

${ }^{3}$ Hong Kong Nang Yan College of Higher Education University, Hong Kong, China.

${ }^{4}$ Will Way Wellbeing RD Ltd, Hong Kong, China.

${ }^{5}$ Tung Wah College, Hong Kong, China.

${ }^{6}$ Xin Hua Hospital Affiliated to Shanghai Jiao Tong University, Shanghai, China.

${ }^{7}$ The Education University of Hong Kong, Hong Kong, China.
Objective: to develop an integrative learning program for people with dementia. Method: a methodological study was conducted using Delphi technique to develop the learning program, followed by a feasibility test. An expert panel was invited to develop the integrative learning program based on the neuroplasticity and learning framework. A feasibility test was conducted to evaluate the implementation of the program in two centers after the training of personnel who run the program. Verbatim transcripts of case conferences were coded, analyzed, and collapsed into themes and sub-themes by consensus. Results: there was no indication for content modification during the period of program implementation. Qualitatively, the participating older adults showed improvement in communications, emotions, connectedness with self and others, and well-being. Conclusion: the integrative learning program was uneventfully implemented with promising results. The program is ready for full-scale research on its efficacy in multiple centers to obtain more robust evidence.

Descriptors: Dementia; Neuroplasticity; Learning; Psychiatric Nursing; Community Health Services; Nursing Methodology Research.

\section{How to cite this article}

Wong TKS, Yang Y, Chen J, Lee CKM, Zhou Y, Jiang L, Tang Q, Chung JWY. Development of an integrative learning program for community dwelling old people with dementia. Rev. Latino-Am. Enfermagem. 2021;29:e3486. [Access $\underset{\text { month }}{\mathrm{f}} \underset{\mathrm{fay}}{\frac{1}{\mathrm{y}}} \mathrm{i}$; ; Available in: DOI: http://dx.doi.org/10.1590/1518-8345.4794.3486 


\section{Introduction}

Caring for the elderly with dementia is a global challenge. About $5 \%$ of the world's elders (47 million) suffered from dementia and it was estimated that this will rise to 75 million in 2030 and 132 million by 2050(1). In other words, there will be one new case of dementia diagnosed globally every 3 seconds. The severity of the problem can be seen by taking China as an example because it has the largest population with dementia in the world(2). The prevalence of senile dementia (among people aged 65 or above) was rising, from 5\% in 2013 to $5.56 \%$ in 2017. Taking the Chinese Mainland, Hong Kong, and Taiwan together, it was reported that the number of people aged 60 or above suffering from dementia was as high as 9.48 million in $2018^{(3)}$. The estimated measures of prevalence of dementia (estimated population) in northern China, central China, southern China, western China, Hong Kong, and Taiwan were 5.5\% (3.52 million), $5.2 \%$ (3.79 million), $4.8 \%$ (1.48 million), $7.2 \%$ (0.69 million), $7.2 \%$ (0.07 million), and $6.0 \%$ (0.15 million) respectively ${ }^{(3)}$. Since China has comparatively quite high dementia prevalence rate, its huge population size will bring huge number of dementia patients with heavy burden on the community. In view of this global problem, the WHO has considered dementia as a global public health priority ${ }^{(4)}$ and taken measures to help countries to contain the problem.

The number of healthy years [disability-adjusted life years (DALY)] lost is tremendous as dementia is the fifth leading cause of death globally. It was reported that about 28.8 million [ $95 \%$ uncertainty interval (UI) 24.5-34.0] DALYs lost were attributed to dementia(5). Dementia also has devastating impacts on sufferers' families and friends. Family members are often the main caregivers for people with dementia. It is an unpaid and round-the-clock job that causes not only physical and psychological exhaustion, but also a huge financial burden. It was reported that the loss of wages for being unpaid caregivers at home was forecasted to increase from $\$ 5$ billion Canadian dollars in 2008 to $\$ 55$ billion Canadian dollars in $2038^{(6)}$. Besides the wage loss, there are also high intangible costs to caregivers in taking care of people with dementia as stress, fatigue, depression, and anxiety set in.

From a societal perspective, the impact of dementia on social healthcare expenditure and demand for nursing services cannot be underestimated as well. As reported, the total global expenditure on dementia treatment in 2015 was US $\$ 818$ billion $^{(7)}$. It was projected this will increase to US $\$ 2$ trillion by 2030 . Similarly, another study estimated that the annual economic losses caused by dementia in mainland China alone was 83.5-97.4 billion
Yuan, and the consumption of cognitive related health services reached 51.3-59.8 billion Yuan a year ${ }^{(8)}$.

The pathogenesis of dementia is complex and scientists are still unraveling its myths from different perspectives, including physiological mechanism of the disease, neurology, behavioral performance, and other associated aspects ${ }^{(9-10)}$. Up to now no conclusion has been reached and the most controversial debate of all is whether dementia is caused by the dysfunction of the neural circuits in the brain(11) or the malfunction of the cerebrovascular system ${ }^{(12)}$. Supporters of the dysfunction in the brain's neural circuits believe that the harmful signals of neuritic plaques and nerve fiber entanglement in certain areas of the brain cause the gradual degradation of the brain's cholinergic system, so they are more inclined to use galantamine drugs to enhance the functions of the sufferers' cholinergic system $^{(13)}$. On the other hand, for those who believe it is the dysfunction in the cerebrovascular system, they believe that high homocysteine affects the blood vessel systolic reactivity of the cerebral artery which in turn leads to cognitive decline and neuro degeneration, so people are advised to take folic acid and vitamin coenzyme to reduce homocysteine levels ${ }^{(14)}$. However, the current pharmacological approach can only delay the progress of the disease. Drug therapy does not cure dementia ${ }^{(1,4)}$.

In recent decades, scientists and clinicians have been exploring various non-pharmacological treatments for dementia to reduce disability, alleviate and/or manage behavioral and mental symptoms so as to improve the quality of life of the affected people and their caregivers $^{(2,6,15)}$. So far, no effective treatment has been identified $^{(1,4)}$.

At present most, if not all, care models adopt a biomedical approach to manage dementia. Most dementia programs are western medicine oriented, e.g., reality orientation, reminiscence therapy, multisensory stimulation, daily life skills training, and music therapy; complementary approach such as inclusion of Chinese medicinal approach has yet to be adopted.

By taking these experiences into consideration, the team attempted to apply the concept of neuroplasticity and learning to dementia care on the premise that people have the capacity to learn new things through repeated practices. In other words, they can rebuild their capacity gradually through the process of slow stream rehabilitation.

Recent studies supported that the brain is plastic ${ }^{(16-17)}$, which means brain cells can change their structure and functions according to the conditions required. In vivo, studies showed that the physical brain structure of mice changed through what they did in their daily experiences 
in enriched environments(18). All brain cells, including those in damaged brains, have neuroplasticity ${ }^{(19)}$ and especially adult neurons are capable of neurogenesis ${ }^{(16)}$. The adult brains have huge latent plasticity and it is believed that repeated practice can lead to re-organization of the cerebral networks which can enhance functional performance through intense training ${ }^{(20)}$.

Learning is a process of acquiring skills, knowledge, attitude and values. The "learnt" experiences would mold the brain through neuroplasticity. Thus, neuroplasticity is vital to learning as new neurons are formed in the hippocampus and cerebellum of the adult brain through neurogenesis, and thus, new memories are created and older memories may be modified(21). The brain can be rewired just by learning, thinking, and practicing. One way to achieve the change is to activate learning through goal setting and practices in a positive mindful manner in the pursuit of rewards while the brain is creating new paths(16-17); and it is always desirable to have a positive environment for neuroplasticity to emerge and learning to take place, when the medial pre-frontal cortex is associated with a healthy, happy, and positive attitude which can be brought about by coming back to the present moment through mindfulness, a way to exercise the pre-frontal cortex ${ }^{(22-23)}$. To further enhance the change, learning, an application of mindfulness, has been shown to increase the flexibility and attention in learning ${ }^{(24)}$ and the learners' connectedness to the surroundings ${ }^{(25-26)}$.

To bridge the knowledge and practice gap in current dementia care, we determined to develop an integrative learning program based on the concept of neuroplasticity and learning. It is hoped that the program will help old people with dementia manage their symptoms using a transdisciplinary approach. We can learn new things (e.g. skills, emotions and cognition) in the presence of innate neuroplasticity. The learning can be conducted in combination of group and personal contact. Group learning allows interaction and stimulation while person-centered learning accommodates individual needs. To have learning to occur, we need to repeatedly practice which optimizes our neural networks based on the neuroplasticity. Therefore, the aim of the study was to develop the integrative learning program for people with dementia.

\section{Method}

This was a methodological study in which an integrative learning program based on the neuroplasticity and learning framework was developed by an expert panel using the Delphi technique, followed by a feasibility test on its implementation using a qualitative approach. Individual interviews with the participants and thematic analysis of verbatim transcripts were carried out. Ethics approval were obtained from the Research Ethics Committee on Human Subjects of the funding agency before the commencement of the study.

\section{The development of the integrative learning program}

Delphi technique was employed to gain consensus in the best possible therapeutic interventions for old people with dementia among members of the expert panel $^{(27-30)}$. The panel consisted of 8 health professionals including a gerontic care nurse, a registered nurse, an occupational therapist, a physiotherapist, a Chinese medicine practitioner, a mindfulness practitioner, a nutritionist, and a neuroscientist. They all had more than 10 years of experience in their own disciplines.

A member of our research team explained to the experts individually the purpose of having the panel and the importance of opinion sharing and idea exchange. Subsequent exchanges covered the conceptual framework, needs of people with dementia, components of the program operation and the intervention protocol. The experts did not meet but to provide their views through emails or audio recordings. We organized, collated the views, presented the aggregated views iteratively to each expert for consideration(28). The exchange on each topic terminated when all experts reached total agreement on their analysis and views were exhausted. Upon completion of each round, a summary was sent to all experts for accuracy checking. With this iterative approach, 12 rounds of exchange were necessitated to develop the complete integrative learning protocol.

To dispel any unrealistic expectations and facilitate learning, training in goal setting skills is needed in the integrative learning program. It was agreed among the experts that people with dementia have different needs and expectations, and various levels of difficulty and ability to meet them, be it basic (novice) or advanced (expert). Hence the panel formulated a list of developmental needs which are necessary and essential for quality living of people with dementia. The goal of development of each need was also identified based on a novice -expert continuum and the conceptual framework of neuroplasticity and learning (Figure 1). 


\begin{tabular}{|c|c|c|c|}
\hline Developmental Needs & Novice Level & Intermediate Level & Expert Level \\
\hline Language & Single word / two words & Simple sentences & Expressions to meet own needs \\
\hline Motor skills & Single move following instructions & Series of moves with good reason & $\begin{array}{l}\text { Free moves (including fine motor } \\
\text { skills) }\end{array}$ \\
\hline Arithmetic & Number & Calculation & Daily application \\
\hline Communication & Response & Interaction & Empathetic communication \\
\hline Self-care & Frequent assistance & Minimal assistance & Independent \\
\hline Relating to self & Body awareness & Spatial awareness & Orientation \\
\hline Relating to others & Recognizing others & Addressing others & Living with others \\
\hline Emotions & Recognizing & Awareness to owning & Expressing \\
\hline
\end{tabular}

Figure 1 - Needs and goals of development on a novice-expert continuum for people with dementia

The panel reviewed some common dementia management programs used in local institutions. Although these programs have included many contemporary treatment modalities, the results were not marked. The panel also commented that the treatment modalities could have been sufficient but the piece-meal approach might undermine their efficacy. They concluded that an integrated and structured multi-modality approach together with emotion management should be adopted for the integrative learning program. The multi-modality treatments in the program were structured sessions that employed physical, cognitive, social, and emotional stimulations to intervene dementia. The modalities selected for the program included reality orientation, daily living skills training, reminiscence therapy, multisensory stimulation, fall prevention program, mindfulness activities, Meridian exercise, brain health program (Four Arts of the Chinese Scholar which referred to zither, go, calligraphy and painting) and health education. It was also agreed that case managers, caregivers, and participants were free to choose these treatments or could be assigned to a treatment regime on a "mix and match" basis to suit their personality traits for improving their abilities to meet their own needs.

Based on the outcome of the above Delphi exercise, the experts brain-stormed the contents and details of each, followed by discussions before resolutions were made by consensus. Consensus was reached for the duration of a standard 3-day protocol and 5-day protocol. The 5-day protocol was an extended version of the 3-day one, which allowed the participants to practice more in a designated time. Figure 2 shows the 3 -day integrative learning protocol. Interventions using the protocol were carried out by case managers who could be nurses, occupational therapists, or other health professionals. These case managers were independent of our research team. To ensure the competency of the case managers, each one had to attend a 3-day training workshop, with one day on theories, another day on practical training by 3 members of the Expert Panel (the gerontic care nurse, the nurse, and the occupational therapist) and the final day on quality assurance.

\begin{tabular}{|c|c|c|c|}
\hline Time & Day 1 & Day 2 & Day 3 \\
\hline $9: 00-9: 30$ & \multicolumn{3}{|c|}{$\begin{array}{c}\text { Preparation for reality orientation information e.g. time, place, persons, news, weather etc. } \\
\text { Communicate with staff for any participants' updates } \\
\text { Greeting with participants and observation on general conditions } \\
\text { Observe and assess the bathing tasks of the participants for giving any safety / training / environmental modification }\end{array}$} \\
\hline $\begin{array}{l}9: 30- \\
10: 00\end{array}$ & \multicolumn{3}{|c|}{ Reality orientation activities } \\
\hline $\begin{array}{l}10: 00- \\
11: 00\end{array}$ & $\begin{array}{c}\text { Meridian and physical exercise program } \\
\text { Active and passive activities and mobilization with gentle massage }\end{array}$ & $\begin{array}{l}\text { Brain health program } \\
\text { Table tasks activities e.g. } \\
\text { arts and crafts / pencil } \\
\text { tasks / cognitive training } \\
\text { activities / goal oriented, } \\
\text { rule-oriented tasks with } \\
\text { end products }\end{array}$ & Mindfulness \\
\hline
\end{tabular}




\begin{tabular}{|c|c|c|c|}
\hline Time & Day 1 & Day 2 & Day 3 \\
\hline $\begin{array}{l}11: 00- \\
11: 30\end{array}$ & $\begin{array}{l}\text { Relaxation program } \\
\text { Music and aroma therapy, gentle stretching / breathing exercise / warm pad }\end{array}$ & $\begin{array}{l}\text { Multisensory stimulation } \\
\text { / Reminiscence program }\end{array}$ & $\begin{array}{l}\text { Fall prevention / Health } \\
\text { education program } \\
\text { Interactive game / } \\
\text { Exercise group }\end{array}$ \\
\hline $\begin{array}{l}11: 30- \\
12: 00\end{array}$ & \multirow{2}{*}{\multicolumn{3}{|c|}{$\begin{array}{c}\text { Lunch time } \\
\text { Feeding assessment / Safety assessment / Health education }\end{array}$}} \\
\hline $\begin{array}{l}12: 00- \\
12: 30\end{array}$ & & & \\
\hline $\begin{array}{l}12: 30- \\
13: 00\end{array}$ & \multicolumn{3}{|c|}{ Daily living skills program - Individual training/functional assessment/consultation } \\
\hline $\begin{array}{l}13: 00- \\
13: 30\end{array}$ & \multicolumn{3}{|c|}{$\begin{array}{l}\text { Communication with staff on any follow-up } \\
\text { Documentation and planning }\end{array}$} \\
\hline
\end{tabular}

Figure 2 - The 3-day integrative learning protocol

\section{Feasibility testing of the integrative learning program using a qualitative approach}

The feasibility test which lasted for 6 months was held in community care centers run by the same non-profit organization (NPO) and their routine and care provided were the same across their centers. The centers were located in different districts where residents were in public housing. Two centers were randomly drawn from the NPO by drawing lots. Eligible older people with dementia from the centers were recruited by convenience sampling. The inclusion criteria were people aged 65 or above, members of the community care centers, diagnosed with dementia and mild cognition impairment (determined by the Montreal Cognitive Assessment Test for Dementia, MoCA score 12.7-20.1 depending on education level) ${ }^{(31)}$. Those living alone, with communication difficulties like language barriers, deafness, dysphasia and/or severe dysarthria, recently participated in another dementia program, with known history of psychotic illnesses such as schizophrenic, psychiatric, or with organic brain diseases such as brain tumors were excluded. All participants continued with their daily routines and medications during the research period. Consents were obtained from both the eligible older people and their relatives.
Qualitative data were based on the verbatim transcripts of the monthly case conferences. The verbatim transcripts of the case conferences were used for thematic analysis. These verbatim records were transcribed and coded for content analysis, based on the conceptual framework of the integrative learning program. A research assistant first identified words/ segments in each transcript and then condensed them into meaningful units. Two members of our research team abstracted all the condensed meaning units into subthemes which were subsequently verified by three external experts.

\section{Results}

The result of the integrative learning program which was reported above for easy reference. The protocol developed from the program was closely followed by the case managers and there was no indication for change throughout the implementation period.

The demographic data showed no significant differences in gender and age between the 2 centers. But there were statistically significant differences in educational level $(p=0.006)$ and duration of dementia $(p=0.001$ ) between the 2 centers (Table 1$)$.

Table 1 - The demographic information of the participants by center. Hong Kong, $2018(\mathrm{~N}=57)$

\begin{tabular}{|c|c|c|c|c|c|c|c|c|}
\hline \multirow{2}{*}{$\begin{array}{l}\text { Demographic Factor } \\
\text { Sex }\end{array}$} & \multicolumn{2}{|c|}{ Center $1^{*}$} & \multicolumn{2}{|c|}{ Center $2^{*}$} & \multicolumn{2}{|c|}{ Total } & \multirow[b]{2}{*}{ Z } & \multirow[b]{2}{*}{$p$-value } \\
\hline & $n$ & $\%$ & $N$ & $\%$ & $n$ & $\%$ & & \\
\hline Female & 34 & 68.0 & 5 & 71.4 & 39 & 68.4 & 0.033 & 1.000 \\
\hline Male & 16 & 32.0 & 2 & 28.6 & 18 & 31.6 & & \\
\hline \multirow[t]{2}{*}{$A g e^{\ddagger}$} & $n$ & Mean (SD) & $N$ & Mean (SD) & $n$ & Mean (SD) & $Z$ & $p$-value \\
\hline & 39 & $85.1(6.59)$ & 6 & $84.7(8.71)$ & 45 & $85.0(6.79)$ & -0.084 & 0.933 \\
\hline
\end{tabular}




\begin{tabular}{|c|c|c|c|c|c|c|c|c|}
\hline \multirow{2}{*}{$\begin{array}{l}\text { Demographic Factor } \\
\text { Education Level }\end{array}$} & \multicolumn{2}{|c|}{ Center $1^{*}$} & \multicolumn{2}{|c|}{ Center $2^{*}$} & \multicolumn{2}{|c|}{ Total } & \multirow[b]{2}{*}{ Z } & \multirow[b]{2}{*}{$p$-value } \\
\hline & $n$ & $\%$ & $n$ & $\%$ & $n$ & $\%$ & & \\
\hline Non-educated & 25 & 65.8 & 2 & 28.6 & 27 & 60.0 & 12.346 & $0.006 \S$ \\
\hline Primary & 13 & 34.2 & 3 & 42.9 & 16 & 35.6 & & \\
\hline Secondary & 0 & 0.0 & 1 & 14.3 & 1 & 2.2 & & \\
\hline Post-secondary & 0 & 0.0 & 1 & 14.3 & 1 & 2.2 & & \\
\hline Duration of Diagnosis & $n$ & $\%$ & $n$ & $\%$ & $n$ & $\%$ & $z$ & $p$-value \\
\hline 3 Months & 11 & 22.0 & 0 & 0.0 & 11 & 19.3 & 14.763 & $0.001 \S$ \\
\hline 5 Months & 26 & 52.0 & 0 & 0.0 & 26 & 45.6 & & \\
\hline 11 Months & 13 & 26.0 & 7 & 100.0 & 20 & 35.1 & & \\
\hline
\end{tabular}

${ }^{*}$ Center 1 is residential center and Center 2 is a day-care center; ${ }^{+}$Fisher's Exact Test was used due to there were cells with expected count less than 5 ; ${ }^{\ddagger}$ Mann-Whitney U Test was used due to small sample size; ${ }^{\S}$ All $p$-values were considered as statistically significant when $p \leqq 0.05$

A total of twelve verbatim records were collected, six from each center. To protect privacy of those not in the study, the team only studied those information related to the participants. With reference to the conceptual framework, communication and well-being were related to neuroplasticity and learning, and life skills reflected neuroplasticity while connectedness reflected mindful learning. Figure 3 shows the results of the content analysis. To ensure the trustworthiness of the analytic process, the team had invited three experienced aged care practitioners (each with at least 5 years of experience in aged care) to join in as content experts to verify the results after the subthemes were identified. They discussed the contents, subthemes and themes until they reach a consensus.

\begin{tabular}{|c|c|c|c|}
\hline Theme & Subtheme & Meaning units & Examples of meaning words/segments \\
\hline \multirow{4}{*}{$\begin{array}{l}\text { Communication } \\
\text { (learning, neuroplasticity) }\end{array}$} & \multirow{2}{*}{$\begin{array}{l}\text { Active } \\
\text { communication }\end{array}$} & Willingness & $\begin{array}{l}\text { Communicate with others, not only family members, but also } \\
\text { therapists }\end{array}$ \\
\hline & & Initiation & $\begin{array}{l}\text { Greet therapists and fellow group members } \\
\text { Answer questions }\end{array}$ \\
\hline & \multirow{2}{*}{$\begin{array}{l}\text { Communication } \\
\text { skills }\end{array}$} & $\begin{array}{l}\text { Means of } \\
\text { expression }\end{array}$ & $\begin{array}{l}\text { Gradual increase in oral expression skills, eye contact, and facial } \\
\text { expression, and vocabulary, volume. More eye contacts and facial } \\
\text { expressions. }\end{array}$ \\
\hline & & $\begin{array}{l}\text { Confidence in } \\
\text { expression }\end{array}$ & $\begin{array}{l}\text { Able to participate in group activities throughout the process and were } \\
\text { happy to cooperate in all training activities. }\end{array}$ \\
\hline \multirow{2}{*}{$\begin{array}{l}\text { Life skills } \\
\text { (neuroplasticity) }\end{array}$} & Activity skills & $\begin{array}{l}\text { Respond with } \\
\text { confidence }\end{array}$ & Willing to participate in training activities and follow instructions \\
\hline & $\begin{array}{l}\text { Functional } \\
\text { performance }\end{array}$ & $\begin{array}{l}\text { Improved self-care } \\
\text { and mobility }\end{array}$ & Increased range of actions and movements \\
\hline \multirow{2}{*}{$\begin{array}{l}\text { Well-being } \\
\text { (learning, neuroplasticity) }\end{array}$} & $\begin{array}{l}\text { Psychological } \\
\text { impact }\end{array}$ & $\begin{array}{l}\text { Positive } \\
\text { temperament }\end{array}$ & A change in temper over weeks \\
\hline & Emotion & Joy & $\begin{array}{l}\text { Laughter gradually increased, and most of the people began to openly } \\
\text { express their pleasure and favorite activities }\end{array}$ \\
\hline \multirow{2}{*}{ Connectedness (learning) } & To self and others & Awareness & $\begin{array}{l}\text { Showed understanding in themselves and being aware of their own } \\
\text { quest for a better life in reminiscence sessions. } \\
\text { Comforting others }\end{array}$ \\
\hline & To others & $\begin{array}{l}\text { Active and } \\
\text { interactive }\end{array}$ & Some took initiative to greet and talk to the therapist. \\
\hline
\end{tabular}

Figure 3 - Content analysis of the case conferences. Hong Kong, 2018 


\section{Discussion}

The participants showed obvious behavioral change which provided an insightful perspective on the effects of the program qualitatively. At the early stages of the program, some participants often left early or frequently asked to go to the bathroom and this situation improved significantly after they had been in contact with the case manager several times. Most participants were able to participate in group activities throughout the process and were happy to cooperate with all training activities. This behavioral change supports that people with dementia have the ability or the desire for self-improvement.

The participants over the 6-month period were increasingly more willing to communicate with others, not only with family members, but also with the case managers, their peers, and the institutional staff. Moreover, they began to use a wider range of oral expression skills with more vocabularies. This was in line with the idea advocated by UK's National Health Service to encourage people with cognitive dysfunction to communicate with others as much as possible in order to slow down the impact of dementia. All participants in the 3-day and 5-day programs showed greater confidence in expressing themselves, using eye contacts, giving facial expressions, and raising their voice volume when answering questions.

After the integrative learning program intervention, most of the participants in the two centers were more confident, more reactive, and had an increased range of actions when doing lower limb exercises. Their willingness to participate in training activities and follow instructions had also improved over time. Similarly, their functional performance (e.g., self-care and mobility) was reported to have improved. The team believes that if this "guidance or encouragement" is not allowed, it affects the overall assessment of functional performance because "guidance or encouragement" is what this group of older people need.

A number of factors lowered the participation rates of some participants, which affected the results. For instance, some participants were unable to join some activities due to infection that required isolation. During an influenza outbreak in the program period, some group activities were restricted and, as a result, the affected participants could only attend personal practice sessions instead. In order to complete all sessions as scheduled, the actual participation time of those affected participants had to be shortened and therefore, could have influenced their performance in the program.

At the early stages of the intervention, the participants showed difficulty in controlling their temper. Their emotional expressions, somehow, drew the attention of the case managers (selected from therapists) who, on reflection, allowed them to make timely adjustments to related activities to better suit the participants' needs. As time went on, laughter in the function room gradually increased, and most of the participants began to express their pleasure and preference in the running of the activities, and established a trusting therapeutic relationship with the case managers and a good rapport was developed between the two parties.

The increase in the participants' pleasure could also be reflected in the verbatim. In the reminiscence sessions, the participants were gradually more willing to share details of their past with others, like recalling where they came from, how they spent their childhood, what their favorite food was, what things impressed them most, and so on, prompting them to start thinking for themselves and being aware of their own quest for a better life. The reminiscence therapy was very effective in an event before the Mid-Autumn festival. The participants were very eager to guess the prices of a variety of mooncakes. Some initiated to compare the prices with those in their old days and to evaluate whether the mooncakes were worth buying. In addition, some participants even took initiative to share the old practice of making monthly instalments to "Moon Cake Club" due to the low wages in the past, the fading out of "Moon Cake Club" etc.

Most of the participants became more active and interactive in the activities, and some out of their own volition began to greet and talk to the case managers, call out the case managers by name correctly, and gradually engage in some daily conversations, which did not occur in the early part of the intervention.

The integrative learning program focused on enhancing the participants' abilities to implement wholeperson care so as to enable institutional caregivers to better meet their needs. It was set up to use physical, cognitive, social, and emotional interventions, as well as some repetitive intervention plans. The repetitive intervention plans focused on developing the elderly's sense of familiarity, security, and abilities in order to increase their participation, learning and development in all their functional areas. Case managers were sensitive to any possible plateau effects that participants might have and, thus, changed the intensity or type of activity components in the affected training sessions.

The program emphasizes self-determination, goal setting and sense of control. The team believes that people must have an understanding of their "self" before they can manage their dementia. The self of a person is manifested in the form of behaviors which evolve from interactions of different personality traits. In the case of the old people, these personality traits would have been shaped to a large extent by their life experiences and have been quite solidly grounded. Their understanding of their 
self is reflected through their behaviors. Therefore, the key to providing good care to people with dementia is to have a shared understanding of mutually acceptable goals among the case managers, caregivers and the old people concerned. This shared understanding means everyone needs to take an active role in the program, not just the recipients of care - the old people ${ }^{(15)}$. Also, it is crucial that the case managers, caregivers and the old people have the same understanding of the old people's "self". This common understanding helps formulate mutually acceptable goals. In this model, people with dementia were the active members in the center of care, while team members shared the roles and responsibilities of caregiving. Transdisciplinary care adopted an approach where case managers were chosen from a team of nurses, occupational therapists, physiotherapists, TCM physicians, western doctors, and pain management specialists basing on care needs.

Given the positive experience that we had in this methodological study, we have committed to actively conduct a multi-center trials to fine-tune the implementation of this transdisciplinary care program so as to benefit more people with dementia. More importantly, this study opens an alternative perspective in dementia care for researchers and those with dementia and their carers.

\section{Conclusion}

This methodological study revealed the feasibility of an integrative approach in the care of old people with dementia. Dementia is considered as a global epidemic with huge potential costs. It is stereotyped by its progressive and irreversible impacts on individual's health and wellbeing. The preliminary work reported in this paper has shed light on the possibility of rehabilitating old people with dementia through the integrative learning program developed from the theories of neuroplasticity and learning. Some positive effects of the program reflected from the results of the observations and judgments of the therapists were evidenced in case conferences. Given this is only a feasibility testing, the research team considered more robust and full scale evaluation of the program necessary and essential for better acceptance. The integrative program may exemplify the contributions of nursing to meet health needs where the demand is growing using a nurse-led model of care.

\section{Acknowledgments}

We are thankful to the participants and their families to take part in the reported study. Without their patience and support, we would have never completed the study.

\section{References}

1. World Health Organization. Global action plan on the public health response to dementia 2017 - 2025 [Internet]. Geneva: World Health Organization; 2017 [cited 2020 Jan 14]. Available from: https://apps.who. int/iris/bitstream/handle/10665/259615/9789241513487eng.pdf; jsessionid=D6561050D5540AFA59F5CFC5212A0 $56 \mathrm{D}$ ? sequence $=1$

2. Chen $Z$, Yang $X$, Song $Y$, Song B, Zhang $Y$, Liu $\mathrm{J}$, et al. Challenges of Dementia Care in China. Geriatrics. 2017;2(1):7. doi: http://doi.org/10.3390/ geriatrics 2010007

3. Wu YT, Ali GC, Guerchet M, Prina AM, Chan KY, Prince $M$, et al. Prevalence of dementia in mainland China, Hong Kong and Taiwan: an updated systematic review and meta-analysis. Int J Epidemiol. 2018;47(3):709-19. doi: http://doi.org/10.1093/ije/dyy007

4. World Health Organization. Towards a dementia plan: A WHO guide [Internet]. Geneva: World Health Organization; 2018. [cited 2020 Jan 14]. Available from: https://apps.who.int/iris/bitstream/hand le/10665/272642/9789241514132-eng.pdf?ua=1

5. GBD 2016 Dementia Collaborators. Global, regional, and national burden of Alzheimers disease and other dementias, 1990-2016: a systematic analysis for the Global Burden of Disease Study 2016. Lancet Neurol. 2019;18(1):88-106. doi: https://doi.org/10.1016/S14744422(18)30403-4

6. Canadian Nurses' Association. Dementia in Canada: Recommendations to support care for Canada's Aging population: Brief prepared for the Senate Standing Committee on Social Affairs, Science and Technology [Internet]. Ottawa: Canadian Nurses' Association; 2016 [cited 2020 Jan 14]. Available from: https://www.cnaaiic.ca/-/media/cna/page-content/pdf-en/dementia-incanada_recommendations-to-support-care-for-canadasaging-population. pdf?la $=$ en\&hash $=4813 \mathrm{DCAB} 22 \mathrm{E} 1 \mathrm{C} 116$ 011B8B6C18F235213BD5A3CB

7. Wimo A, Guerchet M, Ali GC, Wu YT, Prina AM, Winblad $B$, et al. The worldwide costs of dementia 2015 and comparisons with 2010. Alzheimers Dement. 2017;13(1):1-7. doi: http://doi.org/10.1016/j. jalz.2016.07.150

8. Song Y, Wang J. Overview of Chinese research on senile dementia in mainland China. Ageing Res Rev. 2010;Suppl 1:S6-12. doi: http://doi.org/10.1016/j.arr.2010.08.007 9. Charidimou A, Viswanathan A. Multiple neuropathologies and dementia in the aging brain: A key role for cerebrovascular disease? Alzheimers Dement (N Y). 2016;2(4):281-2. doi: http://doi.org/10.1016/j. trci.2016.11.001 
10. Shen $Y$, Ye B, Chen $P$, Wang $Q$, Fan C, Xiang $M$. Cognitive Decline, Dementia, Alzheimer's Disease and Presbycusis: Examination of the Possible Molecular Mechanism. Frontiers Neurosci. 2018;12. doi: http:// doi.org/10.3389/fnins.2018.00394

11. Gratwicke J, Jahanshahi M, Foltynie T. Parkinson's disease dementia: a neural networks perspective. Brain. 2015;138(6):1454-76. doi: http://doi.org/10.1093/brain/ awv104

12. Humpel C. Chronic mild cerebrovascular dysfunction as a cause for Alzheimers disease? Exp Gerontol. 2011;46(4):225-32. doi: http://doi.org/10.1016/j. exger.2010.11.032

13. Freund-Levi $Y$, Jedenius $E$, Tysen-Bäckström AC, Lärksäter M, Wahlund L, Eriksdotter M. Galantamine versus Risperidone treatment of neuropsychiatric symptoms in patients with probable dementia: An open randomized trial. Am J Geriatr Psychiatry. 2014;22(4):341-8. doi: http://doi.org/10.1016/j.jagp.2013.05.005

14. Hainsworth AH, Yeo NE, Weekman EM, Wilcock DM. Homocysteine, hyperhomocysteinemia and vascular contributions to cognitive impairment and dementia (VCID). Biochim Biophys Acta. 2016;1862(5):1008-17. doi: http://doi.org/10.1016/j.bbadis.2015.11.015 15. Bosco A, Schneider J, Coleston-Shields DM, Orrell M. Dementia care model: Promoting personhood through co-production. Arch Gerontol Geriatr. 2019;81:59-73. doi: http://doi.org/10.1016/j.archger.2018.11.003

16. Lillard AS, Erisir A. Old dogs learning new tricks: Neuroplasticity beyond the juvenile period. Dev Rev. 2011;31(4):207-39. doi: http://doi.org/10.1016/j. dr.2011.07.008

17. Lunghi $C$, Sale A. A cycling lane for brain rewiring. Curr Biol. 2015;25(23):1122-r1123. doi: http://doi. org/10.1016/j.cub.2015.10.026

18. Caruso C. New Experiences Help Speed Up Brain Development in Mice: Researchers unravel how new neurons connect to existing neural networks [Internet]. Scientific American. 2016 [cited 2019 Mar 15]. Available from: https://www.scientificamerican.com/article/newexperiences-help-speed-up-brain-development-in-mice/ 19. Särkämö T, Ripollés $P$, Vepsäläinen $H$, Autti $T$, Silvennoinen HM, Salli E, et al. Structural Changes Induced by Daily Music Listening in the Recovering Brain after Middle Cerebral Artery Stroke: A Voxel-Based Morphometry Study. Front Hum Neurosci. 2014;8:245. doi: http://doi.org/10.3389/fnhum.2014.00245

20. Marzouk S. S182 Introduction to neuroplasticity and its application in neurorehabilitation. Clin Neurophysiol. 2017;128(9):e237. doi: http://doi.org/10.1016/j. clinph.2017.07.192

21. Adlaf EW, Vaden RJ, Niver AJ, Manuel AF, Onyilo VC, Araujo MT, et al. Adult-born neurons modify excitatory synaptic transmission to existing neurons. eLife. $2017 ; 6$. doi: http://doi.org/10.7554/eLife.19886

22. Manuello J, Vercelli U, Nani A, Costa T, Cauda F. Mindfulness meditation and consciousness: An integrative neuroscientific perspective. Conscious Cogn. 2016;40:6778. doi: http://doi.org/10.1016/j.concog.2015.12.005 23. Dahlgaard J, Jørgensen MM, Velden AMVD, Sumbundu A, Mehlsen MY. Mindfulness, Health, and Longevity. In: Rattan SIS, Kyriazi M, editors. The Science of Hormesis in Health and Longevity. (Ch22). 2019. Chapter 22, p. 243-55. doi: http://doi.org/10.1016/B978-0-12-814253$0.00022-X$

24. Langer EJ. Mindful learning. Curr Dir Psychol Sci. 2000;9(6):220-3. http://doi.org/10.1111/14678721.00099

25. Wang X, Geng L, Zhou K, Ye L, Ma Y, Zhang S. Mindful learning can promote connectedness to nature: Implicit and explicit evidence. Conscious Cogn. 2016;44:1-7. doi: http://doi.org/10.1016/j.concog.2016.06.006

26. Tang Y, Geng L, Schultz PW, Zhou K, Xiang P. The effects of mindful learning on pro-environmental behavior: A self-expansion perspective. Consc Cogn. 2017;51:1408. doi: http://doi.org/10.1016/j.concog.2017.03.005 27. Mcpherson S, Reese C, Wendler MC. Methodology Update: Delphi studies. Nurs Res. 2018;67(5):404-10. doi: http://doi.org/10.1097/nnr.0000000000000297

28. Flostrand $A$. Finding the future: Crowdsourcing versus the Delphi technique. Bus Horiz. 2017;60(2):229-36. doi: http://doi.org/10.1016/j.bushor.2016.11.007

29. Hasson F, Keeney S. Enhancing rigour in the Delphi technique research. Technol Forecast Soc Change. 2011;78(9):1695-704. doi: http://doi.org/10.1016/j. techfore.2011.04.005

30. Rowe G, Wright G. The Delphi technique: Past, present, and future prospects - Introduction to the special issue. Technol Forecast Soc Change. 2011;78(9):1487-90. doi: http://doi.org/10.1016/j.techfore.2011.09.002I 31. Wong A, Au LWC, Mok VCT, Tang, AKY. What's in the web for family physicians - mild cognitive impairment and dementia. Hong Kong Pract. [Internet]. 2018 [cited 2020 Aug 25];40(1). Available from https://www.hkcfp. org.hk/Upload/HK_Practitioner/2018/hkp2018vol40Mar/ Internet.html

\section{Authors' contribution:}

Study concept and design: Thomas Kwok Shing Wong, Chen Jinghan, Carmen Ka Man Lee, Zhou Ying, Jiang Liping, Joanne Wai Yee Chung. Obtaining data: Yang Yunhua, Chen Jinghan, Carmen Ka Man Lee, Tang Qiubi, Tang Qiubi, Joanne Wai Yee Chung. Data analysis and interpretation: Thomas Kwok Shing Wong, Yang Yunhua, 
Chen Jinghan, Carmen Ka Man Lee, Tang Qiubi, Joanne Wai Yee Chung. Statistical analysis: Thomas Kwok Shing Wong, Yang Yunhua, Chen Jinghan, Carmen Ka Man Lee, Tang Qiubi, Joanne Wai Yee Chung. Obtaining financing: Thomas Kwok Shing Wong. Drafting the manuscript: Joanne Wai Yee Chung. Critical review of the manuscript as to its relevant intellectual content: Thomas Kwok Shing Wong, Zhou Ying, Jiang Liping, Joanne Wai Yee Chung. Others (Access to the pilot study site): Zhou Ying.

All authors approved the final version of the text.

Conflict of interest: the authors have declared that there is no conflict of interest. Creative Commons (CC BY).

This license lets others distribute, remix, tweak, and build upon your work, even commercially, as long as they credit you for the original creation. This is the most accommodating of licenses offered. Recommended for maximum dissemination and use of licensed materials. 